\title{
Preconversion Catalytic Deoxygenation of Phenolic Functional Groups
}

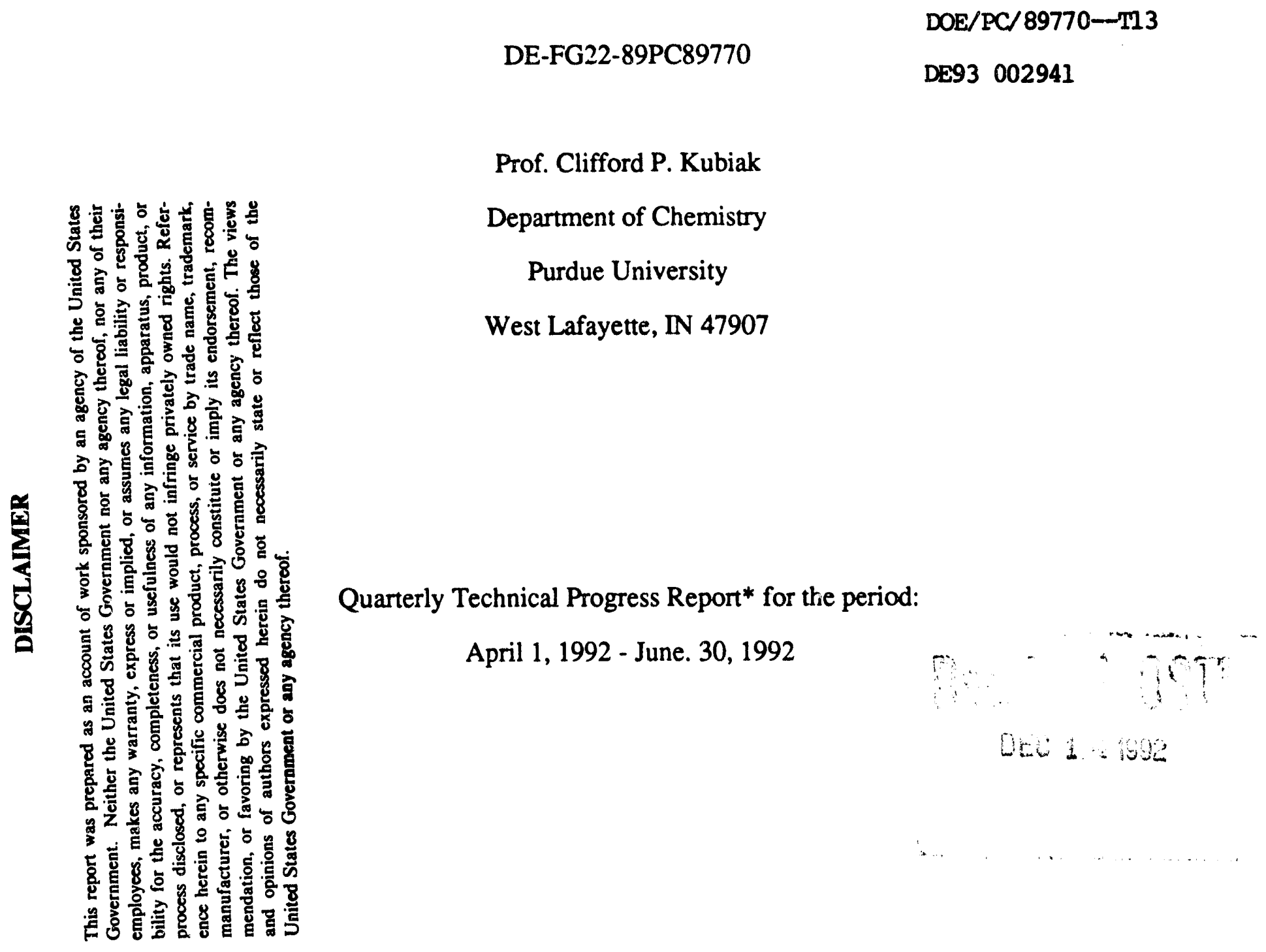

"US/DOE Patent Clearance is not required prior to the publication of this document 


\section{STATEMENT OE PROBLEM:}

The deoxygenation of phenols is a conceptually simple, but unusually difficult chemical transformation to achieve. The phenolic C-O bond energy of $103 \mathrm{kcal} / \mathrm{mol}$ is as strong as a benzene $\mathrm{C}-\mathrm{H}$ bond and over $10 \mathrm{kcal} / \mathrm{mol}$ stronger than the $\mathrm{C}-\mathrm{O}$ bonds of methanol and ethanol.

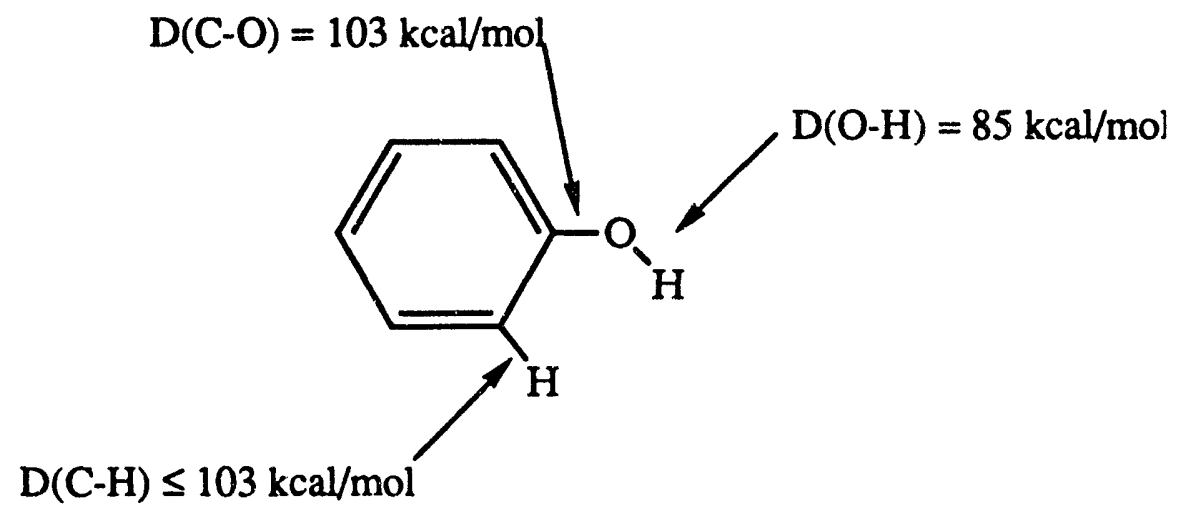

The consequence of this is that the hydrogenation/deoxygenation methods in current use require severe conditions and give low selectivities. The ongoing research described herein is based on the unprecedented, but thermodynamically promising, use of carbon monoxide as the oxygen atom acceptor for the catalytic deoxygenation of phenols.

\section{SIGNIFICANCE OF PROBLEM:}

Aryl carbon-oxygen bond cleavage is a chemical transformation of importance in coal liquefaction and the upgrading of coal liquids ${ }^{1-9}$ as well as in the synthesis of natural products $^{10-17}$. There have been numerous attempts to discover general methods for the cleavage of aryl carbon-oxygen bonds ${ }^{13-15,18-22}$. All the stoichiometric organic methods for phenol deoxygenation have limited applications and involve expensive reagents. Catalytic methods for the hydrodeoxygenation (HDO) of phenols involve supported transition metal oxides, such as $\mathrm{Mo} / \gamma-\mathrm{Al}_{2} \mathrm{O}_{3}, \mathrm{Ni}-\mathrm{Mo} / \gamma-\mathrm{Al}_{2} \mathrm{O}_{3}, \mathrm{Co}-\mathrm{Mo} / \gamma-\mathrm{Al}_{2} \mathrm{O}_{3}$, and $\mathrm{Fe}_{2} \mathrm{O}_{3} / \mathrm{SiO}_{2}$. Typical phenol hydrodeoxygenation conditions involve hydrogen pressures in excess of $100 \mathrm{~atm}$ and temperatures in excess of $200^{\circ} \mathrm{C}$. Under these conditions arene ring hydrogenation is generally found to compete with phenol deoxygenation; and the coproduct water is found to impair the activity of the catalysts. ${ }^{1-5,7,8}$ This proposed research offers the possibility of effecting the selective catalytic deoxygenation of phenolic functional groups using $\mathrm{CO}$. 


\section{RESEARCH BACKGROUND:}

A program of research for the catalytic deoxygenation of phenols, via a low energy mechanistic pathway that is based on the use of the $\mathrm{CO} / \mathrm{CO}_{2}$ couple to remove phenolic oxygen atoms, is underway. The use of readily available $\mathrm{CO}$ as the repository for the phenolic oxygen atom provides both a highly thermodynamically favorable and a kinetically feasible pathway. The deoxygenation of phenols by $\mathrm{CO}$, eq 1 ,

$$
\begin{aligned}
\text { O. } \mathrm{OH}_{(l)}+\mathrm{CO}_{(\mathrm{g})} & \rightleftharpoons \mathrm{OH}(l)+\mathrm{CO}_{2}(\mathrm{~g}) \\
\Delta \mathrm{G}_{298} & =-20.7 \mathrm{kcal} / \mathrm{mol}
\end{aligned}
$$

is thermodynamically favorable by over $20 \mathrm{kcal} / \mathrm{mol}$. However, prior to our studies ${ }^{23}$, examples of oxygen atom transfers from phenols to $\mathrm{CO}$ did not exist. The key to our studies involves the exploitation of the insertion of $\mathrm{CO}$ into the $\mathrm{M}-\mathrm{O}$ bonds of metal phenoxides, eq 2.

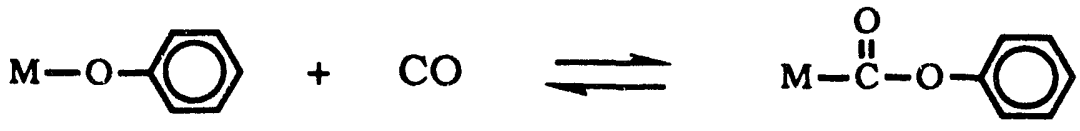

The subsequent decarboxylation, which affords $\mathrm{CO}_{2}$ and a metal phenyl complex ${ }^{23}$, has a high thermodynamic driving force, eq 3.

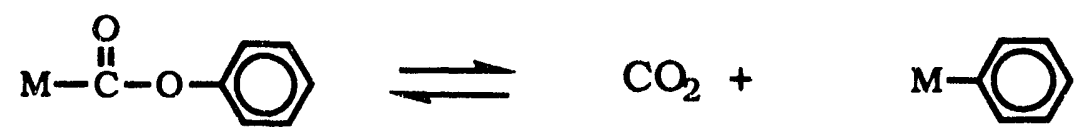

Benzene can be produced by protolysis or hydrogenation, eq 4-5.

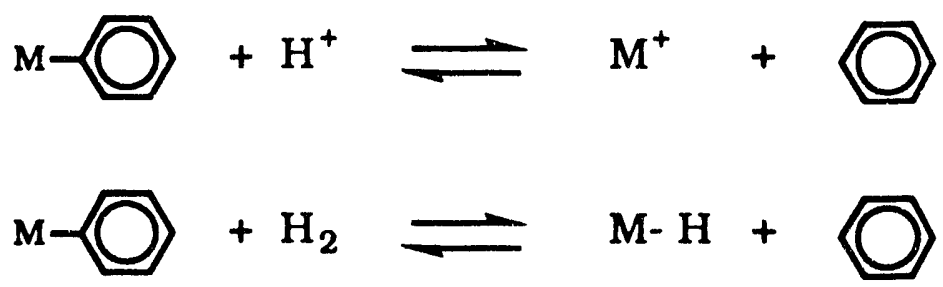

Although our earlier work on the platinum complex, $\mathrm{Pt}(\mathrm{dppe})(\mathrm{OPh}) 2$, achieves the deoxygenation of phenols ${ }^{23}$, this system fell short of our desired goals because the phenyl 
group produced from benzyne is eliminated along with an undeoxygenated aryloxycarbonyl group to yield the ester, phenylbenzoate. Moreover, the deoxygenation reaction is stoichiometric instead of catalytic. We are therefore focusing on systems which have significant promise as catalysts: $\operatorname{Ir}($ triphos $) \mathrm{OPh},[\mathrm{Pt}(\text { triphos }) \mathrm{OPh}]^{+}$and $\mathrm{Rh}$ (triphos)OPh. (triphos = bis(2-diphenylphosphinoethyl)phenylphosphine .

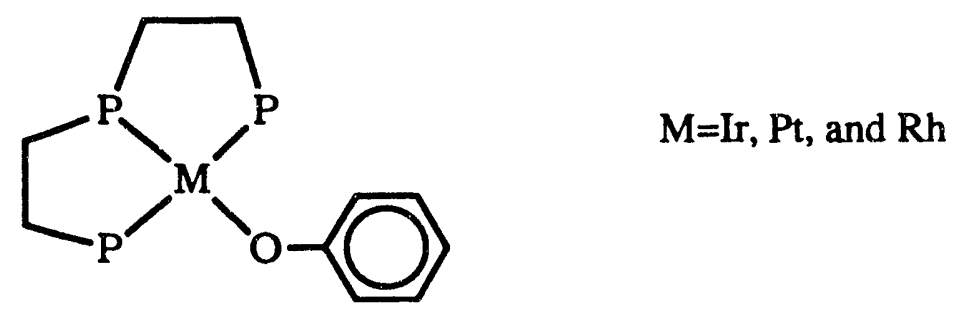

Our studies of phenol deoxygenation focus on monitoring the reactions for the elementary processes upon which catalytic activity will depend: $\mathrm{CO}$ insertion into $\mathrm{M}-\mathrm{OPh}$ bonds, $\mathrm{CO}_{2}$ elimination from aryloxy carbonyls $\{\mathrm{M}-\mathrm{C}(\mathrm{O})-\mathrm{O}-\mathrm{Ph}\}$, followed by formation of a coordinated benzyne intermediate.

\section{RECENT EXPERIMENTAL RESULTS:}

Palladium dppm dimeric systems have been shown by this group to deoxygenate phenols with the unfortunate production of $\mathrm{Pd}^{\circ}$ clusters<smiles>Cc1cccc(C)c1OP1CPP2CP3CP(OP1CP3)P2Oc1c(C)cccc1C</smiles>

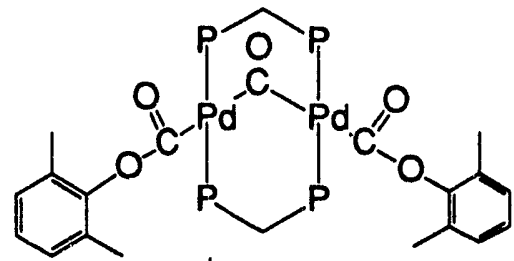<smiles>CC1CCCC1(C)O</smiles><smiles>Cc1cccc(C)c1</smiles>
$\frac{\text { G.C.-MS of volitiles }}{\text { Pd }^{\circ} \text { Clusters }}$

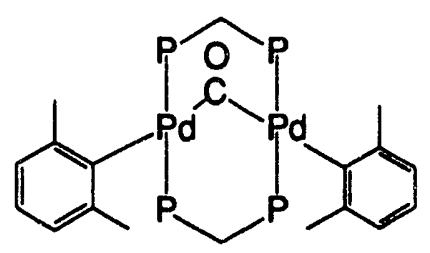


Along with the $\mathrm{Pt}$ (triphos)(O-Ph)PF6 and $\mathrm{Ir}$ (triphos)(O-Ph) systems we are currently working with several dppm bridged platinum dimers.

\section{Preparation of $\mathrm{P}_{2}(\mathrm{~S}-\mathrm{Ph})_{2}(\mathrm{u}-\mathrm{S}-\mathrm{Ph})(\mathrm{u}-\mathrm{dppm})_{2}$}

As a preliminary study $\mathrm{Pt}_{2}(\mathrm{~S}-\mathrm{Ph})_{2}(\mu-\mathrm{S}-\mathrm{Ph})(\mu-\mathrm{dppm})_{2}$ was synthesized by the reaction of $\mathrm{Pt}_{2} \mathrm{Cl}_{2}(\mu-\mathrm{CO})(\mu-\mathrm{dppm})_{2}$ with $\mathrm{NaSPh}$ according to equation 6.<smiles>O=P1(Cl)P2CP3CP(Cl)P(C2)OP1C3</smiles>
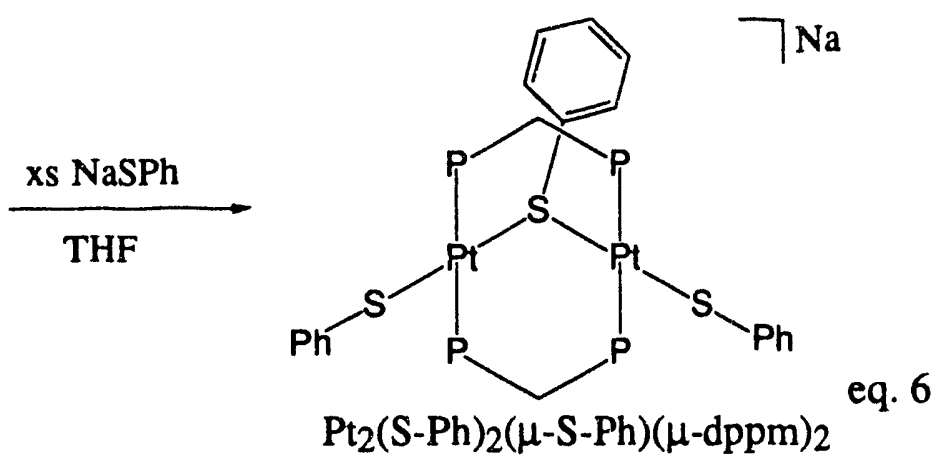

The product has been confirmed by elemental analysis and M.S., with a fragmentation pattern showing three distinct losses of $\mathrm{S}-\mathrm{C}_{6} \mathrm{H}_{5}$. $\mathrm{CO}$ production was confirmed by headspace G.C. Currently crystallographic studies are underway. To date $\mathrm{Pt}_{2}(\mathrm{~S}-\mathrm{Ph})_{2}(\mu$ $\mathrm{S}-\mathrm{Ph})(\mu \text {-dppm })_{2}$ has shown no reactivity with $\mathrm{CO}$ at 100 psi and $55^{\circ} \mathrm{C}$, eq. 7 . This is further evidence for a bridging phenyl mercaptide.

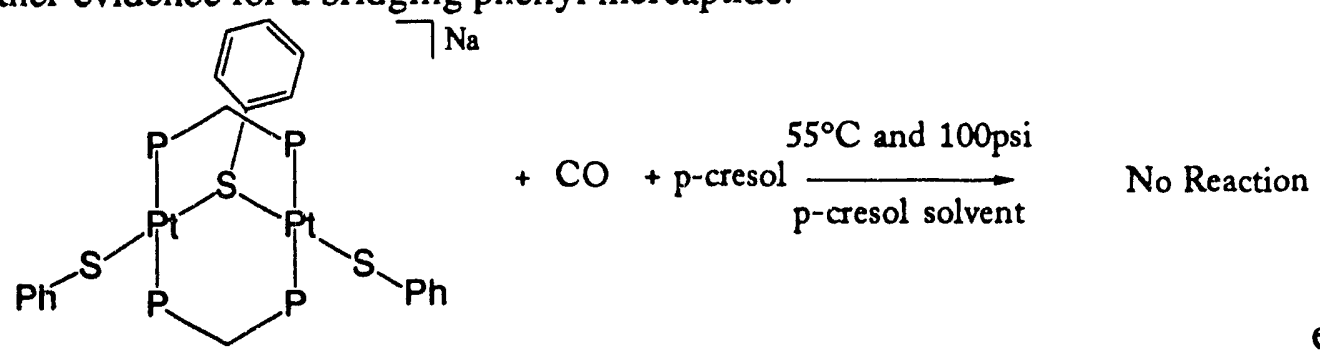

eq. 7

\section{Attempted synthesis of $\mathrm{Pt}_{2} \mathrm{Cl}_{2}(\mu-\mathrm{dppm})(\mathrm{O}-\mathrm{Ph}-\mathrm{Me})_{2}$}

The synthesis of this molecule by metathesis methods has provided either unidentifiable products or no reaction at all. Outlined below are the combinations of reagents attempted to force the halide metathesis. 


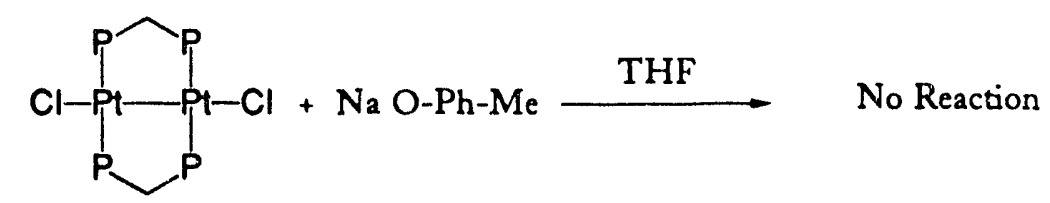

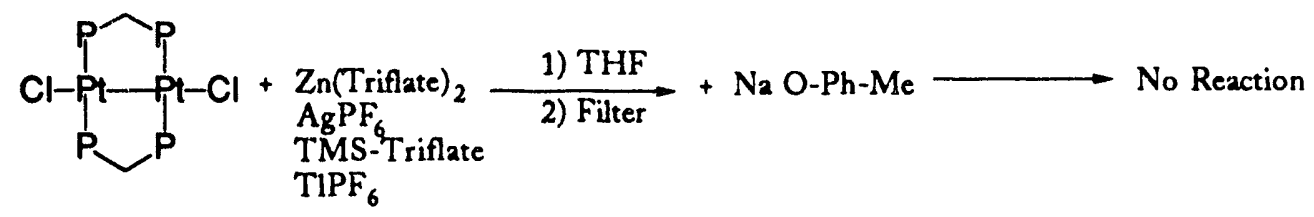

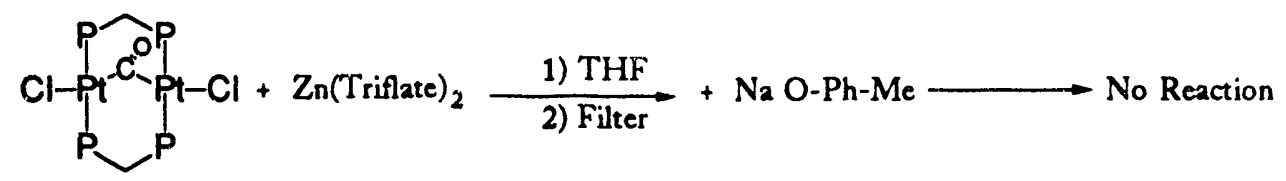

The formation of unstable solvento species is the likely stumbling block for these reactions. The formation of platinum clusters could easily proceed from the anticipated disolvento species. Currently these methasis reactions are being attempted in the presence of excess phenoxide to avoid these problems.

\section{Chemistry of $\mathrm{Pt}_{2} \mathrm{Cl}_{2} \mathrm{H}_{2}(\mu-\mathrm{H})(\mu-\mathrm{dppm})_{2}$}

The related binuclear hydroplatinum complex, $\mathrm{Pt}_{2} \mathrm{Cl}_{2} \mathrm{H}_{2}(\mu-\mathrm{H})(\mu-\mathrm{dppm})_{2}$ has been reported to under go reversible displacement of dihydrogen with carbon monoxide, as well as Water Gas Shift chemistry and we are now exploring this complex as a catalyst precursor.

To date $\mathrm{Pt}_{2} \mathrm{Cl}_{2} \mathrm{H}_{2}(\mu-\mathrm{H})(\mu-\mathrm{dppm})_{2}$ has not reacted with excess p-cresol in refluxing benzene, eq. 8 , nor has the $\mathrm{PF}_{6}$ salt reacted in neat $\mathrm{p}$-cresol at $90^{\circ} \mathrm{C}$, under an active vacuum, eq. 9 .<smiles>O=S(=O)=O</smiles>

20 min Reflux

Benzene
No Reaction

eq. 8 


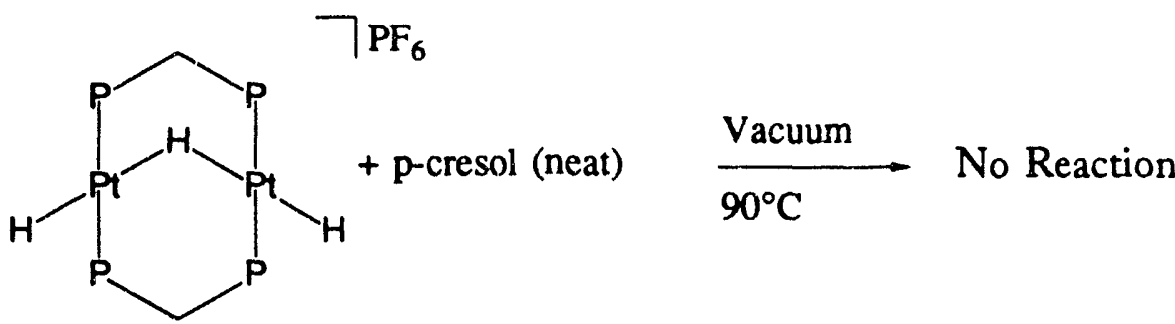

eq. 9

Although, the chloride salt has shown encouraging ${ }^{31}$ P NMR evidence of a partial reaction with the chloride salt at $90^{\circ} \mathrm{C}$, under an active vacuum, eq. 10 . The ${ }^{31 P}$ NMR spectrum shows an $\mathrm{AA}^{`} \mathrm{BB}^{`}$ signal centered at $17 \mathrm{ppm}$ with platinum phosphorus coupling constants indicating the singly substituted molecule, $\mathbf{A}$.

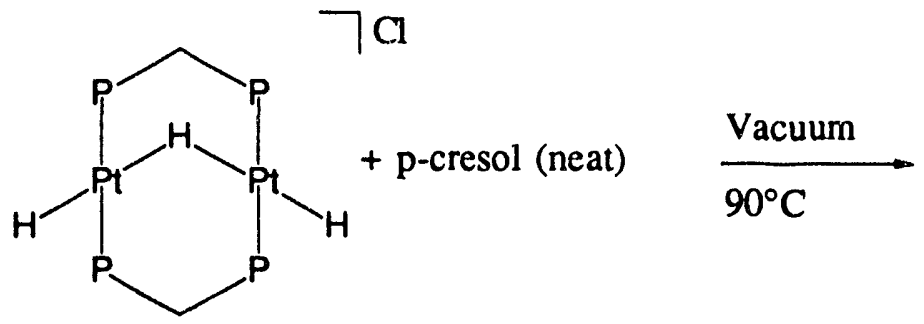<smiles>ClP1P2CP3CP1P(Oc1ccccc1)OP3C2</smiles>

A eq. 10

The p-cresol then is not a strong enough acid to attack the hydrido platinum dimer. In the near future the reactivity of these complexes in the presence of a strong noncoordinating acid will be examined.

\section{CONCLUSION:}

The deoxygenation of phenols by carbon monoxide mediated by $\operatorname{Ir}($ triphos)(OAr) has provided us with a catalytic phenol deoxygenation pathway, through the elimination of $\mathrm{CO}_{2}$ and formation of a benzyne intermediate. Although the $[\mathrm{Pt}($ triphos $)(\mathrm{O}-\mathrm{Ph}-$ Me)]PF6 system is not expected to be as efficient a catalyst as some of the other transition metals systems we are currently exploring, it will provide more information about the deoxygenation mechanism in these triphos complexes. This is due to the presence of the structurally sensitive ${ }^{31} \mathrm{P}-195 \mathrm{Pt}$ coupling constant and comparisons to the extensively studied $\mathrm{Pt}(\mathrm{dppe})(\mathrm{O}-\mathrm{Ph})_{2}$ systems. 


\section{REFERENCES:}

[1] Pelofsky, A. H. ACS Symposium Series 110, American Chemical Society, Washington DC., 1979.

[2] Whitehurst, D. D. ACS Symposium Series 110, American Chemical Society, Washington DC., 1980.

[3] Sullivan, R. F. ACS Symposium Series 100, American Chemical Society, Washington DC., 1981.

[4] Wiegold, H. Euel, 1982, 61, 1021.

[5] Vogelzang, M. W.; Li, C. L.; Schnit, G. C. A.; Gates, B. C.;Petrakis, L. L. Catal, $1983,84,170$.

[6] Li, C. L.; Zu, Z. R.; Cao, Z. A.; Gates, B. C.; Petrakis, L. ALCHE, 1985, 31, 170.

[7] Shabtai, J.; Nag, N. K.; Massoth, F. E. L.Catal, 1983, 104, 413.

[8] Furimsky, E.; Mikhlin, J. A.; Jones, D. Q.; Adly, T.; Baikowitz, H. Can.J.Chem. Eng, 1986, 64, 982.

[9] Hunska, M. K. Polyhedron, 1986, 5, 233.

[10] Peterson, G. A.; Kunng, F.; McCallum, J. S.; Wulff, W. D. Tetrahedron Letters, $1987, \underline{28}, 1381$.

[11] Linders, J. T. M.; Lie, T. S.; Maat, L. Bull. Soc. Chim. Belg, 1988, $27,463$.

[12] Lu, X.; Zhu, J. Synthesis, 1987, 726.

[13] Gross, M. E.; Lankelma, H. P. L.Am. Chem. Soc., 1951, 73, 3439.

[14] Moulton, W. N.; Wade, C. G. J. Org Chem. 1961, 26, 2528.

[15] Hussey, B. J.; Johnstone, R. A. W.; Entwistle, I. D. Tetrahedron, 1982, 38, 3775.

[16] Newman, M. S.; Karnes, H. A. L. Org, Chem. 1966, 31, 3980.

[17] Furukawa, J.; Omura, K. Tetrahedron Letters, 1973, 2631.

[18] Pelletier, S. W.; Locke, D. M. L.Org. Chem, 1958, 23, 131.

[19] Johnstone, R. A. W.; McLean, W. N. Tetrahedron Letters, 1988, 29, 5553. 
[20] Chen, Q.; Yang, Z. Tetrahedron Letters, 1986, 27, 1171.

[21] Echavarren, A. M.; Stille, J. K. L.Am. Chem. Soc, 1987, 109, 5478.

[22] Cacchi, S.; Ciattini, P. G.; Morera, E.; Ortar, G. Tetrahedron Letters, 1986, 27 , 5541.

[23] Ni, J.; Fanwick, P. F.; Kubiak, C. P. L.Am. Chem. Soc, 1990.

[24] Herde, J. L.; Lambert, J. C.; Senoff, C. V. Inorg, Synth, 1974, 15, 18.

[25] Crabtree, R. H.; Burk, M. J. Inorg. Chem, 1986, 25, 931.

[26] King, R.B.; Kapoor, P.N.; Kapoor, R.N Inorg, Chem., 1971, 10, 1841. 

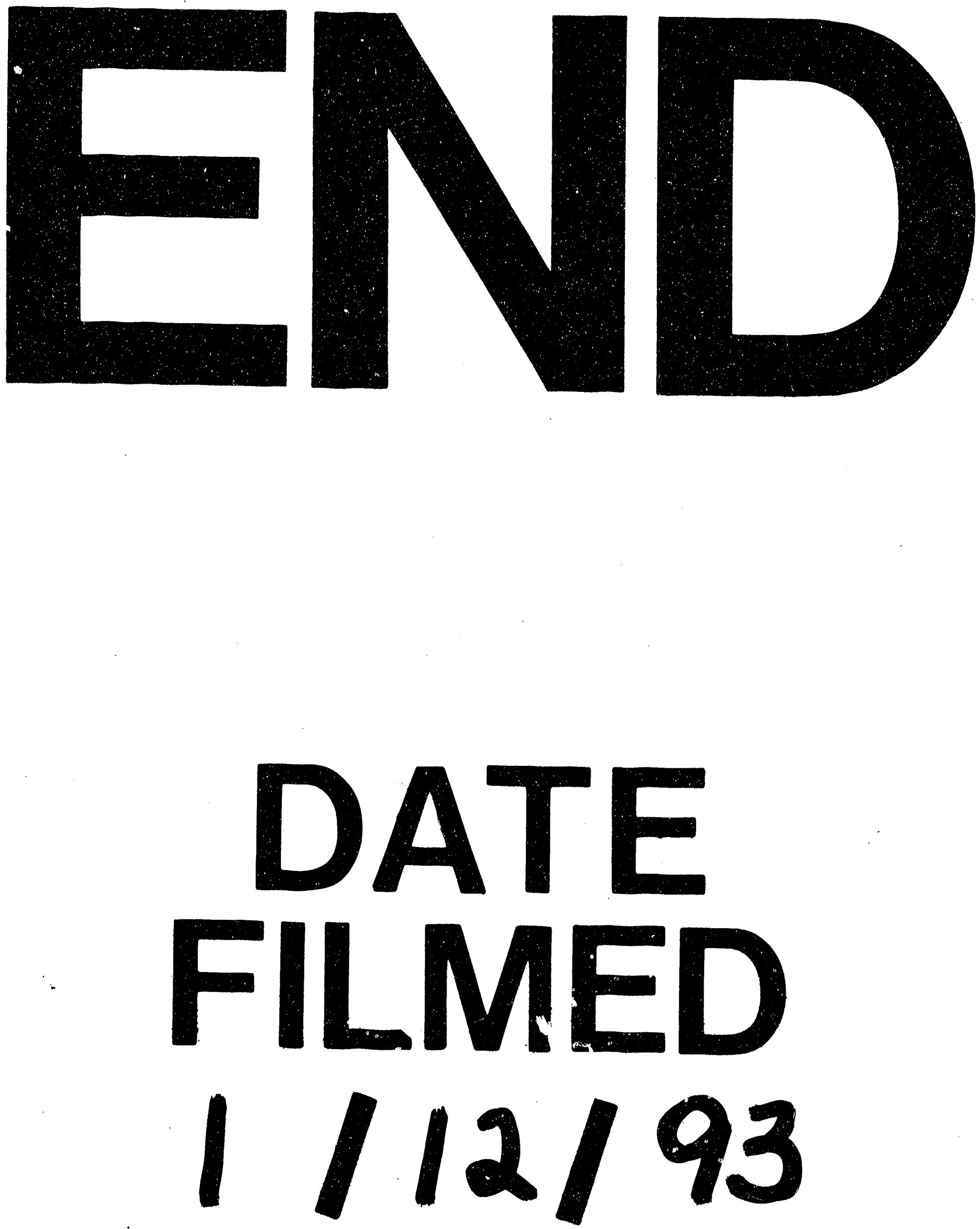


\section{,}

